\title{
The Effect of Bleomycin Embolization on Symptomatic Improvement and Hemangioma Size among Patients with Giant Liver Hemangiomas
}

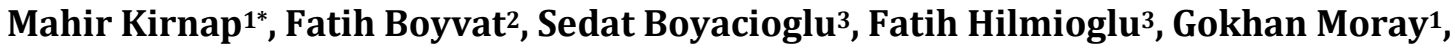 \\ Mehmet Haberal' \\ ${ }^{1}$ Department of Transplant Surgery, Baskent University, Ankara, Turkey \\ ${ }^{2}$ Department of İnterventional Radiology, Baskent University, Ankara, Turkey \\ ${ }^{3}$ Department of Gastroenterology, Baskent University, Ankara, Turkey \\ Email: *mahirkir@hotmail.com
}

How to cite this paper: Kirnap, M., Boyvat, F., Boyacioglu, S., Hilmioglu, F., Moray, G. and Haberal, M. (2018) The Effect of Bleomycin Embolization on Symptomatic Improvement and Hemangioma Size among Patients with Giant Liver Hemangiomas. Open Journal of Gastroenterology, 8, 130-139.

https://doi.org/10.4236/ojgas.2018.84014

Received: February 22, 2018

Accepted: April 27, 2018

Published: April 30, 2018

Copyright $(9) 2018$ by authors and Scientific Research Publishing Inc. This work is licensed under the Creative Commons Attribution International License (CC BY 4.0).

http://creativecommons.org/licenses/by/4.0/

\section{(c) (i) Open Access}

\begin{abstract}
Objective: The optimal treatment of giant liver hemangiomas is controversial. Although surgery is the usual treatment for symptomatic giant hemangiomas, minimally invasive techniques have been recently recommended as an alternative therapy. Aim: we aimed to assess the effect of bleomycin embolization with lipiodol on symptomatic improvement and hemangioma size among patients with symptomatic giant liver hemangiomas. Methods: This study retrospectively involved 17 patients [ 10 women, 7 men; Age range 35 - 67 years (mean $46.41 \pm 2.6$ years)] with giant liver hemangioma who presented to our clinic between August 2014 and October 2016. Bleomycin mixed with lipiodol was administered using selective arterial embolization. The patients were followed by clinical, laboratory, ultrasonography and abdominal tomographic examination (mean $14.47 \pm 2.21$ months). All statistical analyses were performed using SPSS 15.0; a p value of less than 0.05 was considered statistically significant. Results: The mean volume of hemangiomas was $1799.3 \mathrm{~cm}^{3}$ (range $480-9925.1 \mathrm{~cm}^{3}$ ) before the procedure and $405.7 \mathrm{~cm}^{3}$ (range 38.7 $3856 \mathrm{~cm}^{3}$ ) after the procedure. No treatment-related death was observed. All patients demonstrated symptomatic improvement and significant volume reduction $(\mathrm{p}=0.001)$. Conclusions: Minimally invasive bleomycin embolization is an effective alternative to surgery for patients with giant liver hemangiomas.
\end{abstract}

\section{Keywords}

Hemangioma, Liver, Neoplasm, Bleomycin, Lipiodol 


\section{Introduction}

Hemangiomas are benign mesenchymal liver tumors with a prevalence of 3\% $20 \%$ in autopsy series [1]. Hemangiomas most commonly affect women in their fourth and fifth decades of life. Liver hemangiomas are usually asymptomatic, and liver function tests are typically within normal limits. Hence, they mostly detected incidentally. Hemangiomas greater than $5 \mathrm{~cm}$ are referred to as giant hemangiomas, which can be symptomatic and require treatment [2]. Although surgery is the usual treatment method for symptomatic giant hemangiomas, surgical resection continues to be the classical paradigm [3]. Minimally invasive techniques have recently been introduced as alternatives to surgery. In this retrospective study, we aimed to determine the effects of the minimally invasive embolization with bleomycin mixed with lipiodol on mass size and symptoms of patients with giant liver hemangiomas.

\section{Methods}

In the present study 17 patients [10 women, 7 men; Age range $35-67$ years (mean $46.41 \pm 2.6$ years)] with giant liver hemangiomas who presented to our clinic between August 2014 and October 2016 were treated with minimally invasive approach using hemangioma embolization with bleomycin mixed with lipiodol. Two patients underwent a second session of embolization one month later while three patients underwent simultaneous treatment of hemangiomas in two different lobes of the liver. Tumor characterization (length, lesion number) was performed with ultrasonography, computerized tomography (CT) or magnetic resonance imaging. The diagnosis was confirmed by noninvasive examination and the typical angiographic characteristics noted during the Transarterial chemoembolization (TACE) procedure.

Following the placement of a $4 \mathrm{~F}$ introducer into the right femoral artery under standard sterile conditions, the celiac root was selectively cannulized using a $4 \mathrm{~F}$ shepherd hook catheter, and images were taken after contrast material injection. The acquired cine films were used to assess large caliber hypervascular mass lesions supplied by the hepatic artery branch at the side of a liver hemangioma. Following the acquisition of diagnostic images, superselective catheterization of the above-described mass lesions was carried out using a microcatheter and a 0.016-inch guide wire. Bleomycin and lipiodol mixture was injected through amicrocatheterfor the embolization procedure (Figure 1). Fifteen milligrams of bleomycin sulphate [Bleosin-S (in $15 \mathrm{mg}$ vials); Onko/Koc, sel, Turkey] was dissolved in $5 \mathrm{ml}$ saline solution and admixed with $10 \mathrm{ml}$ lipiodol (Laboratoire Guerbet, Fransa) at 1:2 ratio. Lipiodol and bleomycin $(10-20 \mathrm{mg} / \mathrm{ml})$ dosages were determined by tumor diameter $(\mathrm{cm})$, and a maximum of $30 \mathrm{mg}$ bleomycin and $20 \mathrm{ml}$ lipiodolwere used for tumors greater than $10 \mathrm{~cm}$.

During the follow-up, all patients were considered symptomatic due to an increase in hemangioma size. Additionally, eleven patients were considered symptomatic owing to a sense of fullness in the right upper quadrant; five owing to 


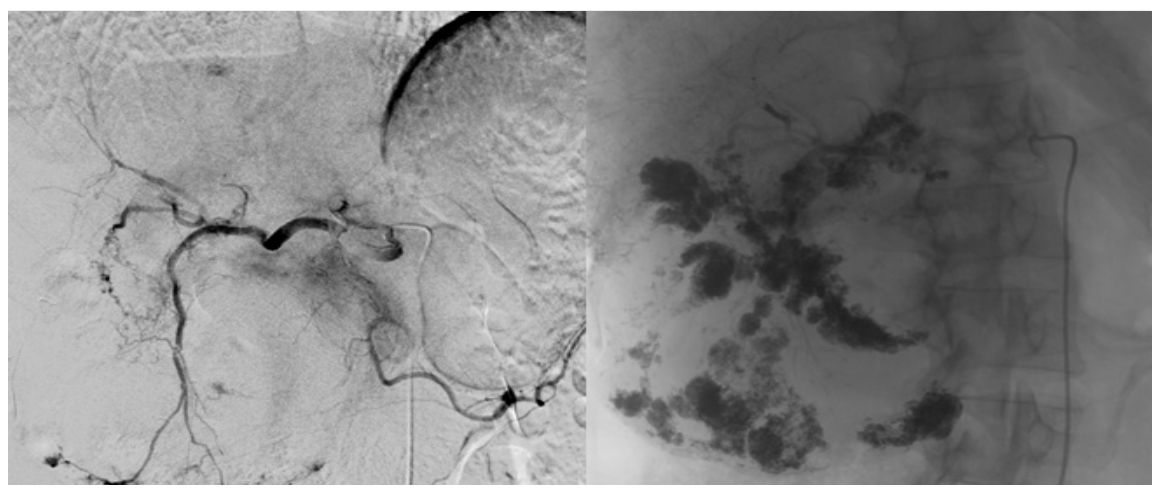

Figure 1. Selective angiographic transarterial chemoembolization procedure.

pain; and one owing to liver failure. All patients were informed about therapeutic and surgical treatment methods currently available for giant liver hemangiomas. All patients gave written informed consent, and the study was approved by the local ethics committee of Başkent University. The main portal vein was patent in all patients. Ascintigraphic examination proved the absence of an arterioportal or arteriovenous shunt. All patients had an INR of less than 1.5 and a thrombocyte count above $50.000 / \mathrm{ml}$. Complete blood count a liver function tests were evaluated before and 1 day after the procedure. All patients were administered analgesics and sedatives prior to the procedure. All patients were administered a single dose (cephazolin 1 gram I.V) prophylactic antibiotic immediately before the procedure. Analgesics and antiemetics were repeated as needed after the procedure. All patients were hospitalized for the embolization procedure. The range of hospital stay was $24-72$ hours ( 24 hours in 15 patients; 48 hours in 1 patient; and 72 hours in 1 patient) and the mean duration of hospital stay was 28 hours.

\section{Bleomycin-lipiodol mixture was prepared as below:}

Tumor size after embolization with bleomycin was assessed by computerized tomography at 1,6 , and 12 months. Hemangioma volume was calculated by multiplying its height, length, and width. The range of the duration of post-procedural clinical and radiological follow-up was 12 to 16 months (mean $14.47 \pm 2.21$ months).

Treatment response was analyzed using SPSS 15.0 (Chicago, USA) software package. Wilcoxon test was used to test whether the distributions of two variables were equal, and the Fired man ANOVA test to compare the median values. Patients age and tumor size was expressed as mean \pm SD; statistical significance was set at $\mathrm{p}=0.05$.

\section{Results}

Seven patients had hemangiomas in the right lobe; 2 in the left lobe, and 8 in both lobes. The diameter of the largest hemangioma was $28 \mathrm{~cm}$. The volumes of the hemagiomas ranged between 480 and $9925.1 \mathrm{~cm}^{3}$. Eleven $(64.8 \%)$ patients were diagnosed with ultrasonography (USG), and $6(35.2 \%)$ with CT. A total of 
22 embolization sessions using the bleomycin lipiodol mixture were carried out for 19 hemangiomas of 17 patients. Radiological examination revealed a marked reduction in the mean hemangioma size after embolization with bleomycin. The largest diameter of hemangiomas was reduced from $14.72 \pm 12.8 \mathrm{~cm}^{3}$ to $7.63 \pm$ $4.76 \mathrm{~cm}^{3}$. The mean volume of the hemangiomas was $3716.276 \mathrm{~cm}^{3}(480.0-$ $\left.9925.1 \mathrm{~cm}^{3}\right)$ prior to the procedure and $746.012 \mathrm{~cm}^{3}\left(38.7-3856 \mathrm{~cm}^{3}\right)$ at 12 months. The pre-procedural hemagioma volumes and diameters were significantly different from one-, six-, and twelve-month values. The mean tumor volume was $746 \pm 405.7 \mathrm{~cm}^{3}$ at 14 months of follow-up.

The mean volume of giant liver hemangiomas was reduced by $54.9 \%$ at 1 month after the procedure compared to the pre-procedural volume $(\mathrm{p}<0.001)$. The volume reduction reached $79.6 \%$ at 6 and 12 months. The non-intervened hemangiomas, on the other hand, were reduced in volume by $50.8 \%$ at 1 month and $75.7 \%$ at 12 months, which was radiologically significant but not statistically significant owing to the low number of hemangiomas (Figure 2 and Figure 3 ).

All patients enjoyed a symptomatic improvement following embolization. Hemangioma-associated pain and sense of fullness mostly started to regress from the first month and completely eliminated by 2 months. The regression of
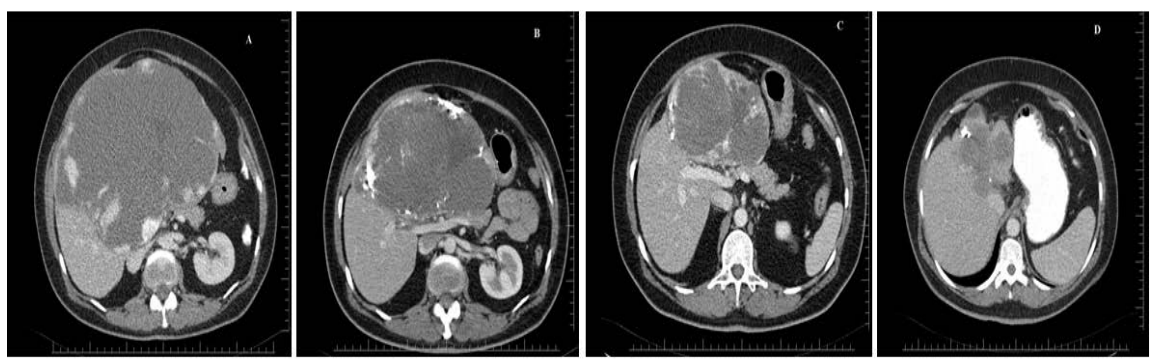

Figure 2. One-year follow-up of a giant liver hemangioma; A: computerized tomographic (CT) examination of the giant liver hemangioma before bleomycin embolization; B: CT examination 1 month after bleomycin embolization; C: CT examination 6months after bleomycin embolization; D: CT examination 12 months after bleomycin embolization.

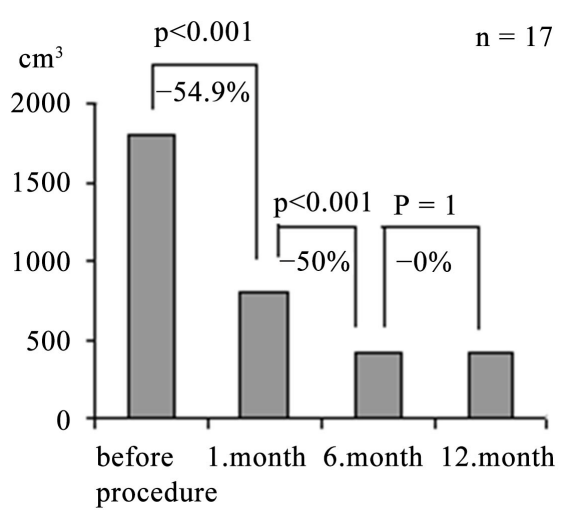

(a)

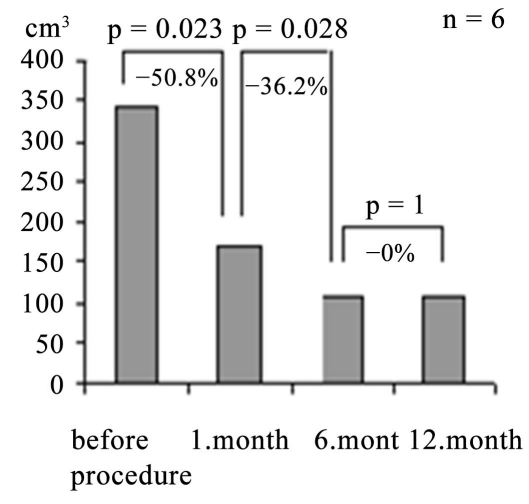

(b)

Figure 3. (a) Comparison of giant hemangioma size at 1, 6, and 12 months after embolization with bleomycin with pre-procedural size; (b) Comparison of the size of the second non-intervened hemangiomas at 1, 6, and 12 months with pre-procedural size. 
the sense of fullness was proportional to a reduction in the size of the mass. No symptom recurrence was observed during the follow-up period.

Seven patients developedpost-procedural postembolization syndrome characterized by pain, fever, loss of appetite or nausea. The most prominent symptom of this syndrome was abdominal pain. Pain in the right upper quadrant started immediately following the procedure in all patients, and subsided by 24 hours in 15 patients and 48 hours in the remainders. Ten patients developed mild nausea and loss of appetite accompanied by pain. Four patients developed asubfebrile body temperature not exceeding $37.5 \mathrm{C}$, which also subsided by 24 hours. No statistically significant increase occurred in liver enzymes (aspartate amino transferase, alanine amino transferase) at 24 hours after the procedure. No clinically meaningful increase occurred in white blood cell count, either. No serious procedural complications developed during follow-up period, such as liver function disorders, liver abscess, or necrosis of normal liver tissue. No patient developed pulmonary symptoms after the procedure. A patient developed a drop in the hemoglobin level that necessitated the infusion of 2 packs of red blood cell suspension. No pathology was detected by a control ultrasonography, and the patient was discharged uneventfully at the end of 72 hours (Table 1).

\section{Discussion}

Cavernous hemangiomas are the most common type of benign tumors of the liver [1] [4]. Most are small, asymptomatic and detected incidentally by radiological screening [5]. Giant cavernous hemangiomas may cause symptoms such as pain, abdominal sense of fullness, and upper abdominal mass. Thrombosis, infarction, intralesional bleeding, capsular distention, and compressing of adjacent organs are the possible causes of pain [6]. In some rare occasions, serious complications such as obstructive jaundice, Kasabach-Merritt syndrome, gastric outlet obstruction, or intra-abdominal hemorrhage due to rupture may occur [7]. Literature data suggest that the risk of rupture of liver hemangiomas ranges between $1 \%$ and $4 \%$. Giant subcapsular lesions may be considered to confer a greater risk [8]. Although hemangiomas do not typically grow in size during follow-up, spontaneous growth constitutes the main treatment indication. Steroids and estrogen therapy may also increase their size. No malignant transformation of hemangiomas has been reported [9]. In accordance with the literature data, our patients suffered from hemangioma growth, sense of abdominal fullness, and pain. The diagnosis was made by diagnostic USG and tomographic examination. Spontaneous growth occurred in hemangiomas during pre-procedural follow-up. No complication developed in any of our patients during a mean follow-up period of 14 months.

The etiology of hemangiomas is not clear. Structurally, hemangiomas are composed of venous pools lined by vascular endothelial cells separated by fibrous tissueseptae. Blood circulation is slow, and hepatic artery is the main source of vascular supply [10]. The treatment options for symptomatic liver hemangiomas 
Table 1. Demographic properties of patients with giant liver hemangiomas (F; Female, M; Male, USG; ultrasonography, CT; computerized tomography).

\begin{tabular}{|c|c|c|c|c|c|c|c|c|c|c|}
\hline Patients & Ages & Sex & Complaint & Diagnosis & Localization & Number & Volume-1 & Volume-2 & Volume-3 & Complication \\
\hline 1 & 42 & $\mathrm{~F}$ & pain/enlargement & CT & bilateral & multiple & 89.6 & 190.4 & 64 & no \\
\hline 2 & 42 & M & pain/enlargement & USG & bilateral & multiple & 880.4 & 797.94 & 39.9 & no \\
\hline 3 & 59 & $\mathrm{~F}$ & $\begin{array}{c}\text { Feeling of } \\
\text { fullness/growth }\end{array}$ & USG & bilateral & 2 & 4576 & 405 & & low hemoglobin \\
\hline 4 & 47 & $\mathrm{~F}$ & $\begin{array}{c}\text { Feeling of } \\
\text { fullness/growth }\end{array}$ & USG & bilateral & multiple & 510.3 & & & $\begin{array}{l}\text { fever and } \\
\text { vomiting }\end{array}$ \\
\hline 5 & 48 & M & $\begin{array}{c}\text { Feeling of } \\
\text { fullness/growth }\end{array}$ & USG & bilateral & 3 & 946 & 470.7 & & no \\
\hline 6 & 54 & $\mathrm{~F}$ & $\begin{array}{l}\text { Feeling of } \\
\text { fullness/growth }\end{array}$ & CT & Right lob & 1 & 600 & & & no \\
\hline 7 & 39 & $\mathrm{~F}$ & $\begin{array}{c}\text { Feeling of } \\
\text { fullness/growth }\end{array}$ & USG & Right lob & 1 & 101 & & & no \\
\hline 8 & 48 & $\mathrm{~F}$ & pain/enlargement & USG & Bilateral & multiple & 600 & & & no \\
\hline 9 & 67 & $\mathrm{~F}$ & pain/enlargement & $\mathrm{CT}$ & Right lob & 1 & 1340.9 & & & no \\
\hline 10 & 49 & $\mathrm{~F}$ & pain/enlargement & USG & Right lob & 2 & 3021 & 4 & & no \\
\hline 11 & 47 & $\mathrm{~F}$ & $\begin{array}{c}\text { Feeling of } \\
\text { fullness/growth }\end{array}$ & $\mathrm{CT}$ & Right lob & 1 & 770 & & & no \\
\hline 12 & 35 & M & $\begin{array}{c}\text { Feeling of } \\
\text { fullness/growth }\end{array}$ & USG & Right lob & 1 & 658 & & & no \\
\hline 13 & 52 & M & $\begin{array}{c}\text { Feeling of } \\
\text { fullness/growth }\end{array}$ & USG & Left lob & multiple & 831.6 & & & no \\
\hline 14 & 40 & M & $\begin{array}{l}\text { growth/Liver } \\
\text { failure }\end{array}$ & $\mathrm{CT}$ & bilateral & multiple & 3705 & & & no \\
\hline 15 & 37 & M & $\begin{array}{l}\text { Feeling of } \\
\text { fullness/growth }\end{array}$ & USG & bilateral & multiple & 144 & 229 & 108 & no \\
\hline 16 & 45 & F & $\begin{array}{c}\text { Feeling of } \\
\text { fullness/growth }\end{array}$ & USG & Left lob & multiple & 1510.2 & & & no \\
\hline 17 & 38 & M & $\begin{array}{c}\text { Feeling of } \\
\text { fullness/growth }\end{array}$ & $\mathrm{CT}$ & Right lob & 1 & 810 & & & no \\
\hline
\end{tabular}

include steroids, radiotherapy, surgical resection, hepatic artery ligation, and transarterial embolization (TACE) [11]. Asymptomatic liver hemangiomas, on the other hand, have no definitive indications for surgery, although they must be closely monitored due to the risk of growth [3].

The decision for performing surgery for liver hemangiomas should be carefully weighed against the complication risk. A number of series have reported serious blood loss $(10 \%-27 \%)$ and death at a rate of $0 \%-2 \%$ after the enucleation or resection of hepatic hemangiomas [10]. Surgical resection is controversial even in the case of symptomatic hemangiomas owing to the risk of severe complications. The definitive indications for surgery include intraperitoneal bleeding, intratumoral bleeding, and consumption coagulopathy (Kasabach-Merritt syndrome) and spontaneous or traumatic rupture. Nevertheless, spontaneous rupture is an extremely rare complication even with giant heman- 
giomas [8]. As reported previously, other definitive indications for surgery, such as Kasabach-Merritt syndrome, can also be corrected by embolization [12]. Surgery should be reserved for patients with giant liver hemangiomas in whom the non-surgical treatment fails. Although our patients had no contraindication for surgery, they were successfully treated in a minimally invasive manner, i.e. by embolization with bleomycin. By this way, they were protected against the complications of surgery.

Recent studies have emphasized the importance of the role of TACE to treat symptomatic hemangiomas as an effective treatment method that is less invasive than surgery [4]. To date, several different embolic agents like gelatin sponge, steel coils, polyvinyl alcohol (PVA), ethanol, sodium morphate, and isobuthylcyano-acrylate have been used to treat hemangiomas [13]. However, liquid embolic agents like PVA and sodium morphate or ethanol may lead to serious complications such as severe pain, and may cause reflux embolization. Gelatin sponge alone does not destroy blood sinuses [14]. Bleomycin is an antimycotic and antimicrobial agent used against squamous cell carcinomas, testis cancers, and malignant lymphomas. Its antineoplastic activity stems from its inhibition of DNA biosynthesis [15]. Oikawa et al. [16] first reported the antiangiogenic action of bleomycin in 1990. Bleomycin exerts a local sclerosingaction on endothelial cells. Bleomycin, alone or mixed with iodized oil (lipiodol), can be used as a sclerosing agent to treat vascular anomalies [17]. The mechanism of the antiangiogenic effects of bleomycin is unknown. Animal studies have suggested that injury starts in capillaries in the form of endothelial cell pyknosis, thrombocyte aggregation, and intraluminal thrombus formation, ultimately inducing fibroblast proliferation and collagen deposition [18]. Pulmonary fibrosis is the most severe pulmonary complication of bleomycin. Bleomycin-induced pulmonary fibrosis has not been reported for doses used to treat hemangiomas, however [18]. Pulmonerfibrosis is seen in $30 \%$ of patients in whom the cumulative bleomycin dose exceeds $450 \mathrm{mg}$ [15]. In this study, the maximum bleomycin dose was substantially lower than the toxic dose; we therefore encountered no case of pulmonary fibrosis.

Lipiodol (iodized oil) is used as an embolic agent and an anticancer drug carrier. It is selectively accumulated in vascular sinuses [19]. Lipiodol not only invades small arteries supplying a tumor, but it also carries bleomycin to it. Arteriovenous shunts inside hepatic cavernous hemangiomas are extremely rare [20]. Studies on animals and humans have demonstrated that lipiodol remains in small arteries and sinusoids of a tumor [19]. The mechanism of effect of bleomycin mixed with lipiodolis thought to be the destruction of endothelial cells and formation of microthrombin in sinuses, ultimately resulting in the atrophy and fibrosis [14]. Additionally, bleomycin mixed with lipiodol does not harm normal blood vessels. This study demonstrated a variable reduction of hemangioma size at 3 - 12 months after embolization. The difference between hemangiomas size post-and pre-embolization was statistically significant. 
We suggest that bleomycin and lipiodol have a superior effect on embolization than solid embolic agents. Bleomycin mixed with lipiodol acts not only as an embolization agent, but also as a chronic sclerozing agent that induces fibrosis. The fibrotic effect of bleomycin mixed with lipiodolas well as the redcution in hemangioma size and blood supply of hemangiomas were radiologically showed during 12-month follow-up of the patients.

Thanks to its relatively modest embolization effect, bleomycin mixed with lipiodol is safer than liquid embolic agents like sodium morphate and ethanol. The most common side effects of embolization are pain, fever, leucocytosis, and nausea. The postembolization syndrome lasts several days and serious complications are rare [21]. Our patients suffered mild-moderate postembolization syndrome, and none of them developed liver failure. Even a patient with preexisting liver failure tolerated the procedure well. This may be due to lipiodol being not taken by a normal hepatic tissue but rapidly cleared through hemangiomatous sinusoids.

\section{Conclusion}

This retrospective study showed that the embolization of giant liver hemangiomas with bleomycin and lipiodol mixture eliminated symptoms and reduced lesion size. Embolization with bleomycin mixed with lipiodol is an effective alternative to surgery in these patients.

\section{Conflict of Interest}

The authors declare no conflict of interest.

\section{Author Contributions}

Mahir Kirnap designed and performed the research; Fatih Boyvat performed the research; Sedat Boyacioğlu, Fatih Hilmioglu, Gokhan Moray and Mehmet Haberal analyzed the data.

\section{Supportive Foundations}

We don't any supported foundations.

\section{Institutional Review Board Statement}

All patients gave written informed consent, and the study was approved by the local ethics committee of Başkent University.

\section{Informed Consent Statement}

All study participants, and their legal guardian, provided informed written consent prior to study enrollment.

\section{Conflict-of-Interest Statement}

The authors declare no conflict of interest. 


\section{Data Sharing Statement}

No additional data are available.

\section{References}

[1] Choi, B.Y. and Nguyen, M.H. (2005) The Diagnosis and Management of Benign Hepatic Tumors. Journal of Clinical Gastroenterology, 39, 401-412. https://doi.org/10.1097/01.mcg.0000159226.63037.a2

[2] Weimann, A., Ringe, B., Klempnauer, J., et al. (1997) Benign Liver Tumors: Differential Diagnosis and Indications for Surgery. World Journal of Surgery, 21, 983-990. https://doi.org/10.1007/s002689900337

[3] Schnelldorfer, T., Ware, A.L., Smoot, R., et al. (2010) Management of Giant Hemangioma of the Liver: Resection versus Observation. Journal of the American College of Surgeons, 211, 724-730.

https://doi.org/10.1016/j.jamcollsurg.2010.08.006

[4] Giavroglou, C., Economou, H. and Ioannidis, I. (2003) Arterial Embolization of Giant Hepatic Hemangiomas. CardioVascular and Interventional Radiology, 26, 92-96. https://doi.org/10.1007/s00270-002-2648-8

[5] Sun, J.H., Nie, C.H., Zhang, Y.L., Zhou, G.H., Ai, J., Zhou, T.Y., Zhu, T.Y., Zhang, A.B., Wang, W.L. and Zheng, S.S. (2015) Transcatheter Arterial Embolization Alone for Giant Hepatic Hemangioma. PloS One, 10, Article ID: e0135158.

https://doi.org/10.1371/journal.pone.0135158

[6] Erdogan, D., Busch, O.R., van Delden, O.M., et al. (2007) Management of Liver Hemangiomas According to Size and Symptoms. Journal of Gastroenterology and Hepatology, 22, 1953-1958. https://doi.org/10.1111/j.1440-1746.2006.04794.x

[7] Ribeiro, M.A.F.Jr., Papaiordanou, F., Gonc, alves, J.M., et al. (2010) Spontaneous Rupture of Hepatic Hemangiomas: A Review of the Literature. World Journal of Hepatology, 2, 428-433. https://doi.org/10.4254/wjh.v2.i12.428

[8] Jain, V., Ramachandran, V., Garg, R., et al. (2010) Spontaneous Rupture of a Giant Hepatic Hemangioma-Sequential Management with Transcatheter Arterial Embolization and Resection. Saudi Journal of Gastroenterology, 16, 116-119. https://doi.org/10.4103/1319-3767.61240

[9] Glinkova, V., Shevah, O., Boaz, M., et al. (2004) Hepatic Haemangiomas: Possible Association with Female Sex Hormones. Gut, 53, 1352-1355. https://doi.org/10.1136/gut.2003.038646

[10] Ho, H.Y., Wu, T.H., Yu, M.C., et al. (2012) Surgical Management of Giant Hepatic Hemangiomas: Complications and Review of the Literature. Chang Gung Medical Journal, 35, 70-78.

[11] Herman, P., Costa, M.L., Machado, M.A., et al. (2005) Management of Hepatic Hemangiomas: A 14-Year Experience. Journal of Gastrointestinal Surgery, 9, 853-859. https://doi.org/10.1016/j.gassur.2005.01.292

[12] Malagari, K., Alexopoulou, E., Dourakis, S., et al. (2007) Transarterial Embolization of Giant Liver Hemangiomas Associated with Kasabach-Merritt Syndrome: A Case Report. Acta Radiologica, 48, 608-612. https://doi.org/10.1080/02841850701326917

[13] Soyer, P. and Levesque, M. (1995) Hemoperitoneum Due to Spontaneous Rupture of Hepatic Haemangiomatosis: Treatment by Superselective Arterial Embolization and Partial Hepatectomy. Australasian Radiology, 39, 90-92. https://doi.org/10.1111/j.1440-1673.1995.tb00243.x 
[14] Zeng, Q., Li, Y., Chen, Y., et al. (2004) Gigantic Cavernous Hemangioma of the Liver Treated by Intra-Arterial Embolization with Pingyangmycin-Lipiodol Emulsion: A Multi-Center Study. CardioVascular and Interventional Radiology, 27, 481-482. https://doi.org/10.1007/s00270-003-2754-2

[15] Bennett, J.M. and Reich, S.D. (1979) Bleomycin. Annals of Internal Medicine, 90, 945-948. https://doi.org/10.7326/0003-4819-90-6-945

[16] Oikawa, T., Hirotani, K., Ogasawara, H., et al. (1990) Inhibition of Angiogenesis by Bleomycin and Its Copper Complex. Chemical and Pharmaceutical Bulletin, 38, 1790-1792.

[17] Chen, Y., Li, Y., Zhu, Q., et al. (2008) Fluoroscopic Intralesional Injection with Pingyangmycin Lipiodol Emulsion for the Treatment of Orbital Venous Malformations. American Journal of Roentgenology, 190, 966-971.

https://doi.org/10.2214/AJR.07.2851

[18] Duncan, I.C. and Van Der Nest, L. (2004) Intralesional Bleomycin Injections for the Palliation of Epistaxis in Hereditary Hemorrhagic Telangiectasia. American Journal of Neuroradiology, 25, 1144-1146.

[19] Ohishi, H., Uchida, H., Yoshimura, H., et al. (1985) Hepatocellular Carcinoma Detected by Iodized Oil. Use of Anticancer Agents. Radiology, 154, 25-29. https://doi.org/10.1148/radiology.154.1.2981114

[20] Bozkaya, H., Cinar, C., Besir, F.B., et al. (2014) Minimally Invasive Treatment of Giant Haemangiomas of the Liver: Embolisation with Bleomycin. CardioVascular and Interventional Radiology, 37, 101-107. https://doi.org/10.1007/s00270-013-0618-y

[21] Leung, D.A., Goin, J.E., Sickles, C., et al. (2001) Determinants of Postembolization Syndrome after Hepatic Chemoembolization. Journal of Vascular and Interventional Radiology, 12, 321-326. https://doi.org/10.1016/S1051-0443(07)61911-3 